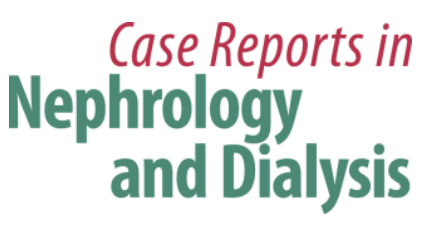

Case Rep Nephrol Dial 2016;6:53-60

DOI: $10.1159 / 000445428$

Publisnea onithe: IVIarch 30, 2016

\title{
Treatment of Focal Segmental Glomerulosclerosis Recurrence in the Renal Allograft: A Report of Two Cases
}

\author{
Minh-Ha Tran ${ }^{a}$ Cynthia Chan ${ }^{b}$ Whitney Pasch ${ }^{c}$ Philip Carpenter ${ }^{a, d}$ \\ Hirohito Ichii ${ }^{e}$ Clarence Foster ${ }^{\mathrm{e}}$ \\ ${ }^{a}$ Department of Pathology and Laboratory Medicine, UC Irvine Health School of Medicine, \\ and ${ }^{b}$ Department of Pharmacy, UC Irvine Health Medical Center, Inpatient Pharmacy, \\ Orange, Calif., 'UCLA Olive View, and 'Department of Pathology, Keck School of Medicine, \\ University of Southern California, Los Angeles, Calif., and ${ }^{\circledR}$ Division of Transplantation, \\ Department of Surgery, UC Irvine Health School of Medicine, Orange, Calif., USA
}

\section{Key Words}

Focal segmental glomerulosclerosis · Renal allograft · Kidney transplantation · Complications of kidney transplantation - Therapeutic plasma exchange - Intravenous immune globulin .

Rituximab

\begin{abstract}
Focal segmental glomerulosclerosis (FSGS) causes glomerular lesions that can progress to end-stage renal disease. It is suspected to be caused by a circulating factor that is amenable to plasmapheresis removal and exhibits a risk for recurrence in the renal allograft. We present two patients with FSGS recurrence in their allograft kidneys diagnosed by biopsy after significant proteinuria developed in the posttransplant setting. Treatment with therapeutic plasma exchange induced long-term remission in both patients. Spot urine protein:creatinine ratios were monitored and treatment was continued until a target of $<0.5$ was achieved. In patient number two, a second peak in proteinuria and azotemia was ultimately attributable to ureteral stenosis and these values normalized following repair. In conclusion, therapeutic plasma exchange is an effective treatment for FSGS recurring following renal transplant.
\end{abstract}




\section{Case Reports in \\ Nephrology \\ and Dialysis}

Case Rep Nephrol Dial 2016;6:53-60

\begin{tabular}{l|l} 
DOI: $10.1159 / 000445428$ & (C) 2016 The Author(s). Published by S. Karger AG, Basel \\
\hline
\end{tabular} www.karger.com/cnd

Tran et al.: Treatment of Focal Segmental Glomerulosclerosis Recurrence in the Renal Allograft: A Report of Two Cases

\section{Introduction}

Focal segmental glomerulosclerosis (FSGS) is a clinicopathologic entity responsible for up to $20 \%$ of all cases of end-stage kidney disease in the United States. The incidence of FSGS is estimated at 7 per million individuals annually, has a slight male predominance (male: female ratio 1.5-2), and now represents the leading cause of idiopathic nephrotic syndrome in adults [1].

Although the pathogenesis of FSGS has not yet been fully described, the lesions that are induced include tuft collapse, segmental hyalinosis, and effacement of foot processes as revealed by electron microscopy [2]. FSGS may also occur secondarily to certain genetic predispositions as well as disorders such as sickle cell disease, HIV nephropathy, and obesity; in these instances, plasma exchange would not be considered a primary therapeutic option and treatment would instead be directed at the underlying driver [2]. Clinically, patients with FSGS manifest significant, nephrotic-range proteinuria, reduced renal function, and hypertension.

Eighty percent of FSGS cases are characterized as primary and are suspected to be caused by a circulating FSGS permeability factor, a low-molecular weight anionic protein [3]. This same factor may be responsible for the recurrence of FSGS in the renal allograft, a scenario that occurs in approximately $20-50 \%$ of primary allografts, most commonly within the first 3 months following transplant $[4,5]$. Plasmapheresis removal of this factor appears to effectively treat many such cases $[6,7]$.

Recurrent FSGS can be suspected in patients who develop impaired graft function and significant proteinuria, defined as $>1 \mathrm{~g} / 24 \mathrm{~h}$ in the posttransplant period. In many cases, proteinuria can develop acutely within a few days after transplant. Early recognition is therefore critical in properly diagnosing and managing this disorder. If recurrent FSGS is suspected (even in the absence of a pretransplant history of FSGS) then it is important to inform the pathology department of this suspicion so that biopsy specimens can be properly processed for electron microscopy, which is needed to evaluate for the foot process effacement characteristic of FSGS.

The American Society for Apheresis guidelines designate recurrent FSGS in the renal allograft as a category I indication for therapeutic plasma exchange (grade 1B, strong recommendation) [8]. We present two patients who developed recurrences of FSGS in their primary renal allografts treated with plasmapheresis and intravenous immune globulin (IVIG).

\section{Case 1}

A 39-year-old Hispanic male with a history of end-stage renal disease (ESRD), hypertension and hypertrophic cardiomyopathy underwent deceased donor renal transplantation with thymoglobulin induction and standard steroid taper. He developed poor graft function and nephrotic-range proteinuria beginning on posttransplant day 1 . He required posttransplant hemodialysis on posttransplant days $3,6,8$, and 11 , as well as initiation of therapeutic plasma exchange and IVIG on postoperative day 5. Renal transplant biopsies obtained on posttransplant day 7 confirmed the team's suspicion for FSGS recurrence in the renal allograft. The patient's treatment course is depicted in figure 1. Pretreatment and posttreatment biopsies are depicted in figure 2 . The patient is currently 4 years posttransplant and continues to demonstrate excellent renal allograft function (serum creatinine of 1.6) with continued absence of proteinuria. 


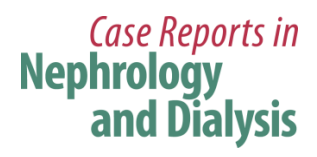

Case Rep Nephrol Dial 2016;6:53-60 \begin{tabular}{l|l}
\hline DOI: $10.1159 / 000445428$ & $\begin{array}{l}\text { C } 2016 \text { The Author(s). Published by S. Karger AG, Basel } \\
\text { www.karger.com/cnd }\end{array}$
\end{tabular}

Tran et al.: Treatment of Focal Segmental Glomerulosclerosis Recurrence in the Renal Allograft: A Report of Two Cases

\section{Case 2}

A 37-year-old Asian male with ESRD due to primary FSGS underwent living unrelated renal transplantation performed with thymoglobulin induction followed by standard steroid taper. On posttransplant day 3, significant proteinuria and a rise in serum creatinine developed. Therapeutic plasma exchange was initiated on posttransplant day 4 and continued forward as noted in figure 3. The patient also received a single dose of rituximab as well as IVIG as treatment for his recurrent FSGS. A kidney biopsy on posttransplant day 8 was negative for rejection, but demonstrated typical foot process effacement changes consistent with FSGS recurrent in the renal allograft. Following an initial complete response to therapeutic plasma exchange by posttransplant day 78, renal dysfunction and proteinuria recurred. A repeat allograft biopsy was obtained, which demonstrated improvement in the degree of foot process effacement and no evidence for rejection. The second bout of allograft dysfunction was ultimately discovered to be due to interval development of high-grade stenosis in the allograft ureter leading to a postobstructive nephropathy. Surgical correction of this abnormality led to normalization of his values. As of posttransplant day 317, blood urea nitrogen and creatinine (both as $\mathrm{mg} / \mathrm{dl}$ ) are 13 and 1.3, respectively, and there is continued absence of proteinuria.

\section{Discussion}

We describe two cases of FSGS recurrent in the primary allografts successfully treated with therapeutic plasma exchange. In both cases, remission was associated with resolution of proteinuria and histologic improvement in the degree of foot process effacement on electron microscopy.

Our findings are similar to the experiences of others. In one case series, 10/11 patients resulted in a persistent reduction in 24-hour urine protein following 5-11 (mean of 6) therapeutic plasma exchange procedures in conjunction with immunosuppressant medications [9]. In another study, patients with recurrent FSGS not managed with plasma exchange were used as historic controls and were compared to 13 patients treated with plasma exchange. While persistent proteinuria contributed to graft loss in all untreated controls, 11/13 (85\%) patients treated with plasma exchange achieved either complete or partial remission [4]. In another report, three of five patients with early recognition of recurrent FSGS treated with plasma exchange responded well, resulting in the reversal of foot process effacement and remission of proteinuria [5]. Among 14 pediatric patients with FSGS recurrent in the renal allograft, 9 were treated with 10 cycles of plasma exchange (3 cycles per week, the same regimen as ours) with $5 / 9$ (55.5\%) and $1 / 9$ (12\%) achieving complete and partial remissions, respectively; no remissions were observed among the 5 patients not treated with plasma exchange [10].

In a treatment series of FSGS recurrent in the renal allograft, Alachkar and colleagues [11] noted a complete response rate in 9/25 (36\%) and partial response in 10/25 (25\%) of patients treated with combinations of plasmapheresis and rituximab. Interestingly, levels of soluble urokinase-type plasminogen activator (suPAR) - a prospective permeability factor elevated in up to two thirds of those with primary FSGS - were found to correlate both with recurrence and response [11,12]. suPAR, however, is not specific for FSGS and has shown to be elevated in immune activation states, such as sepsis, HIV infection, and paroxysmal nocturnal hemoglobinuria, among others [13]. Furthermore, suPAR rebounds quickly following 


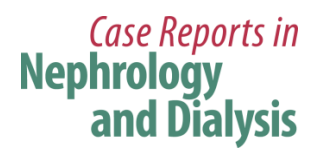

Case Rep Nephrol Dial 2016;6:53-60

DOI: 10.1159/000445428

C 2016 The Author(s). Published by S. Karger AG, Basel www.karger.com/cnd

Tran et al.: Treatment of Focal Segmental Glomerulosclerosis Recurrence in the Renal Allograft: A Report of Two Cases

plasma exchange, and clinical response associated with plasma exchange treatment occurred despite sustained reductions in suPAR levels [14].

Alternative therapies for recurrent FSGS are being explored. The overall efficacy of rituximab in recurrent FSGS is unclear. Rodriguez-Ferrero et al. [15] showed no improvement in proteinuria upon addition of rituximab to chronic plasma exchange therapy in three retransplanted patients with recurrent FSGS. Yabu and colleagues [16] had a similar negative result with rituximab. In contrast, Kumar and colleagues [17], upon retrospective review, identified complete responses [defined as reduction in urine protein:creatinine (Pr: $\mathrm{Cr}$ ) ratio to $<0.2$ ] and partial responses (defined as decrease in urine $\mathrm{Pr}: \mathrm{Cr}$ ratio by $50 \%$ and $<2.0$ ) among $2 / 8$ and $4 / 8$ pediatric patients with recurrent FSGS. There have also been cases of responses to rituximab after incomplete or absent response to plasma exchange [18-20].

The precise mechanism of rituximab, a monoclonal antibody directed against CD20, merits further research. A CD20-independent mechanism was studied by Fornoni and colleagues [21], who described marked disruption of the actin cytoskeleton of podocytes exposed to FSGS sera. Rituximab, through binding and preservation of sphingomyelin-related enzymes (sphingomyelin phosphodiesterase acid like 3B-SMPDL-3b; acid sphingomyelinase), partially prevented the cytoskeletal damage incited by FSGS sera, thus protecting the podocyte filtration barrier and preserving function. This mechanism was corroborated by Takahashi and colleagues [22], who demonstrated that rituximab, but not purified IgG, significantly reduced proteinuria in an Adriamycin-induced nephropathy rat model. This appears to be related to binding of rituximab to glomerular SMPDL-3b and protection of podocyte-related proteins, nephrin and podocin. Although precise mechanisms require further research to elucidate, the authors provide a theory that SMPDL-3b is a key factor in the actin-cytoskeleton remodeling process within podocytes and that rituximab binding to SMPDL-3b provides a salutary effect.

Evidence appears to support a similar protective action of cyclosporine A on podocytes [23], which blocks calcineurin-mediated desphosphorylation of synaptopodin, thus preserving cytoskeleton stability and preventing foot process effacement [24]. There is also evidence of reduction in proteinuria with higher-dose intravenous (but not standard-dose oral) cyclosporine. However, the long-term safety and efficacy remain in question [25].

Inhibition of the renin-angiotensin system (RAS) also has an antiproteinuric effect in recurrent FSGS patients. In one report [26], authors used triple RAS suppression with angiotensin-converting enzyme inhibitor, angiotensin receptor blocker, and aliskiren, a direct renin inhibitor. Their patient was treated with a combination of rituximab and plasma exchange, and the sequential triple RAS inhibition by the latest addition of aliskiren led to a significant reduction in recalcitrant proteinuria.

In a study by Gohh et al. [27], preemptive plasma exchange treatment was explored as a means of reducing posttransplant FSGS recurrence in ten patients considered at high risk for recurrence (ESRD within 3 years of FSGS diagnosis or advanced azotemia at presentation or prior allograft loss due to recurrent FSGS). At a mean of $751 \pm 314$ days, seven patients had excellent continued graft function. Three patients, each of whom had already manifested previous graft loss due to recurrent FSGS, developed biopsy-proven recurrence in the allograft. Two of these patients returned to dialysis; the third remained nephrotic with a creatinine of $2.6 \mathrm{mg} / \mathrm{dl}$ at the time of publication.

Park and colleagues [28], in an observational cohort study, found no difference in FSGS recurrence rates whether adult kidney transplant patients received pretransplant plasma exchange $(1 / 4,25 \%)$, pretransplant plasma exchange plus rituximab $(1 / 5,20 \%)$ or no pretreatment $(5 / 18,27.7 \%)$. 


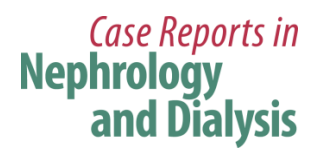

\begin{tabular}{l|l}
\hline Case Rep Nephrol Dial 2016;6:53-60 \\
\hline DOI: 10.1159/000445428 & $\begin{array}{l}\text { ○ 2016 The Author(s). Published by S. Karger AG, Basel } \\
\text { www.karger.com/cnd }\end{array}$ \\
\hline
\end{tabular}

Tran et al.: Treatment of Focal Segmental Glomerulosclerosis Recurrence in the Renal Allograft: A Report of Two Cases

In the pediatric population, Gonzalez and colleagues [29] found absent protective effect of pretransplant plasma exchange with recurrence rates of 47 and $63 \%$, respectively, for living and deceased donor first-time kidney transplantation. However, preemptive treatment did lead to a lower than expected rate of recurrence among patients undergoing transplant who had previously lost a graft due to recurrence. Among those with recurrences, plasma exchange was highly effective as a treatment modality with $88 \%$ complete or partial remission rate.

\section{Conclusion}

In patients referred for renal transplantation, a vague diagnosis of 'hypertensive nephrosclerosis' - particularly in younger patients - raises concern for the absence of a clearly defined etiology for primary renal failure. In some cases, a primary disorder such as FSGS may have been causative. This is of particular concern considering the high risk of recurrence of primary FSGS in the renal allograft. The development of significant proteinuria following transplant should raise concern for this possibility. FSGS recurrent in the renal allograft can be diagnosed on electronic microscopy in proteinuric patients. The prompt institution of therapeutic plasma exchange is an important treatment modality, and rituximab may be added to this as adjunctive therapy. Further research is required regarding the role of rituximab therapy either as a therapeutic modality in established FSGS recurrence or possibly as pretransplant prophylaxis to reduce the risk of recurrence. Monitoring of treatment response to ongoing plasmapheresis treatment is accomplished through measurement of urine spot Pr:Cr ratios and serum creatinine. In responding patients, treatment should be continued until proteinuria has been reliably suppressed to below $0.5 \mathrm{~g} /$ day.

\section{Statement of Ethics}

The authors have no ethical conflicts to disclose

\section{Disclosure Statement}

C.C., M.-H.T., W.P., P.C., and C.F. have no relevant conflicts to disclose. H.I. was in part supported by grants from NIH-NCRR UL1 TR000153, KL2 TR000147, and the Juvenile Diabetes Research Foundation International 17-2011-609.

\section{References}

1 Kitiyakara C, Kopp JB, Eggers P: Twenty-one year trend in ESRD due to focal segmental glomerulosclerosis in the United States. Am J Kidney Dis 2004;44:815-825.

-2 Gbadegesin R, Lavin P, Foreman J, Winn M: Pathogenesis and therapy of focal segmental glomerulosclerosis: an update. Pediatr Nephrol 2011;26:1001-1015.

-3 Sharma M, Sharma R, McCarthy ET, Savin VJ: The focal segmental glomerulosclerosis permeability factor: biochemical characteristics and biological effects. Exp Biol Med (Maywood) 2004;229:85-98.

4 Deegens JK, Andresdottir MB, Croockewit S, Wetzels JF: Plasma exchange improves graft survival in patients with recurrent focal glomerulosclerosis after renal transplant. Transpl Int 2004;17:151-157.

-5 Artero M, Biava C, Amend W, Tomlanovich S, Vincenti F: Recurrent focal glomerulosclerosis: natural history and response to therapy. Am J Medicine 1992;92:375-383. 
Tran et al.: Treatment of Focal Segmental Glomerulosclerosis Recurrence in the Renal Allograft: A Report of Two Cases

6 Savin VJ, Sharma R, Sharma M, McCarthy ET, Swan SK, Ellis E, Lovell H, et al: Circulating factor associated with increased glomerular permeability to albumin in recurrent focal segmental glomerulosclerosis. $\mathrm{N}$ Engl J Med 1996;334:878-883.

7 Artero ML, Sharma R, Savin VJ, Vincenti F: Plasmapheresis reduces proteinuria and serum capacity to injure glomeruli in patients with recurrent focal glomerulosclerosis. Am J Kidney Dis 1994;23:574-581.

-8 Schwartz K, Winters JL, Padmanabhan A, Balogun RA, Delaney M, Linenberger ML, Szczepiorkowski ZM, Williams ME, Wu Y, Shaz BH: Guidelines on the use of therapeutic apheresis in clinical practice-evidencebased approach from the Writing Committee of the American Society for Apheresis: the sixth special issue. J Clin Apher 2013;28:145-284.

-9 Shariatmadar S, Noto TA: Therapeutic plasma exchange in recurrent focal segmental glomerulosclerosis following transplantation. J Clin Apher 2002;17:78-83.

10 Garcia CD, Bittencourt VB, Tumelero A, Antonello JS, Malheiros D, Garcia VD: Plasmapheresis for recurrent posttransplant focal segmental glomerulosclerosis. Transplant Proc 2006;38:1904-1905.

11 Alachkar N, Wei C, Arend LJ, Jackson AM, Racusen LC, Fornoni A, et al: Podocyte effacement closely links to suPAR levels at time of posttransplantation focal segmental glomerulosclerosis occurrence and improves with therapy. Transplantation 2013;96:649-656.

12 Wei C, Hindi EI, Li J, Fornoni A, Goes N, Sageshima J, et al: Circulating urokinase receptor as a cause of focal segmental glomerulosclerosis. Nat Med 2011;17:952-960.

13 Thuno M, Macho B, Eugen-Olsen J: suPAR: the molecular crystal ball. Dis Markers 2009;27:157-172.

14 Staeck O, Slowinski T, Lieker I, Wu K, Rudolph B, Schmidt D, et al: Recurrent primary focal segmental glomerulosclerosis managed with intensified plasma exchange and concomitant monitoring of soluble urokinase-type plasminogen activator receptor-mediated podocyte $\beta 3$-integrin activation. Transplantation 2015;99:2593-2597.

15 Rodriguez-Ferrero M, Ampuero J, Anaya F: Rituximab and chronic plasmapheresis therapy of nephrotic syndrome in renal transplantation patients with recurrent focal segmental glomerulosclerosis. Transplant Proc 2009; 41:2406-2408.

-16 Yabu JM, Ho B, Scandling JD, Vincenti F: Rituximab failed to improve nephrotic syndrome in renal transplant patients with recurrent focal segmental glomerulosclerosis. Am J Transplant 2008;8:222-227.

$\checkmark 17$ Kumar J, Shatat IF, Skversky AL, Woroniecki RP, Del Rio M, Perelstein EM, et al: Rituximab in post-transplant pediatric recurrent focal segmental glomerulosclerosis. Pediatr Nephrol 2013;28:333-338.

-18 Gossmann J, Scheuermann EH, Porubsky S, Kachel HG, Geiger H, Hauser IA: Abrogation of nephrotic proteinuria by rituximab treatment in a renal transplant patient with relapsed focal segmental glomerulosclerosis. Transpl Int 2007;20:558-562.

$\checkmark 19$ Cho JH, Lee JH, Park GY, Lim JH, Kim JS, Kang YJ, et al: Successful treatment of recurrent focal segmental glomerulosclerosis with a low dose rituximab in a kidney transplant recipient. Ren Fail 2014;36:623-626.

20 Stewart ZA, Shetty R, Nair R, Reed AL, Brophy PD: Case report: successful treatment of recurrent focal segmental glomerulosclerosis with a novel rituximab regimen. Transpl Proc 2011;43:3994-3996.

21 Fornoni A, Sageshima J, Wei C, Merscher-Gomez S, Aguillon-Prada R, Jauregui AN, et al: Rituximab targets podocytes in recurrent focal segmental glomerulosclerosis. Sci Transl Med 2011;3:85ra46.

-22 Takahashi Y, Ikezumi Y, Saitoh A: Rituximab protects and exerts anti-proteinuric effects in rat Adriamycininduced nephropathy independent of B-lymphocytes. Nephrology (Carlton) 2016, DOI: 10.1111/nep.12737. Epub ahead of print.

23 Faul C, Donnelly M, Merscher-Gomez S, Chang YH, Franz S, Delfgaauw J: The actin cytoskeleton of kidney podocytes is a direct target of the antiproteinuric effects of cyclosporine A. Nat Med 2008;14:931-938.

24 Coppo R: Different targets for treating focal segmental glomerular sclerosis. Contrib Nephrol 2013;181:8490.

25 Cravedi P, Kopp JB, Remuzzi G: Recent progress in the pathophysiology and treatment of FSGS recurrence. Am J Transplant 2013;13:266-274.

-26 Freiberger V, Amann K, Heemann U, Frank H: Effect of a triple blockade of the renin-angiotensin-system in recurrent focal segmental glomerulosclerosis after kidney transplantation. Transpl Int 2009;22:1110-1113.

27 Gohh RY, Yango AF, Morrissey PE, Monaco AP, Gautam A, Sharma M, McCarthy ET, Savin VJ: Preemptive plasmapheresis and recurrence of FSGS in high-risk renal transplant recipients. Am J Transplant 2005;5:2907-2912.

28 Park HS, Hong Y, Sun IO, Chung BH, Kim HW, Choi BS, et al: Effects of pretransplant plasmapheresis and rituximab on recurrence of focal segmental glomerulosclerosis in adult renal transplant recipients. Korean J Intern Med 2014;29:482-488.

29 Gonzalez E, Ettenger R, Rianthavorn P, Tsai E, Malekzadeh M: Preemptive plasmapheresis and recurrence of focal segmental glomerulosclerosis in pediatric renal transplantation. Pediatr Transplant 2011;15:495-501. 


\section{Case Reports in \\ Nephrology and Dialysis}

\begin{tabular}{l|l|}
\hline Case Rep Nephrol Dial 2016;6:53-60 \\
\hline DOI: 10.1159/000445428 & $\begin{array}{l}\text { @ 2016 The Author(s). Published by S. Karger AG, Basel } \\
\text { www.karger.com/cnd }\end{array}$ \\
\hline
\end{tabular}

Tran et al.: Treatment of Focal Segmental Glomerulosclerosis Recurrence in the Renal Allograft: A Report of Two Cases

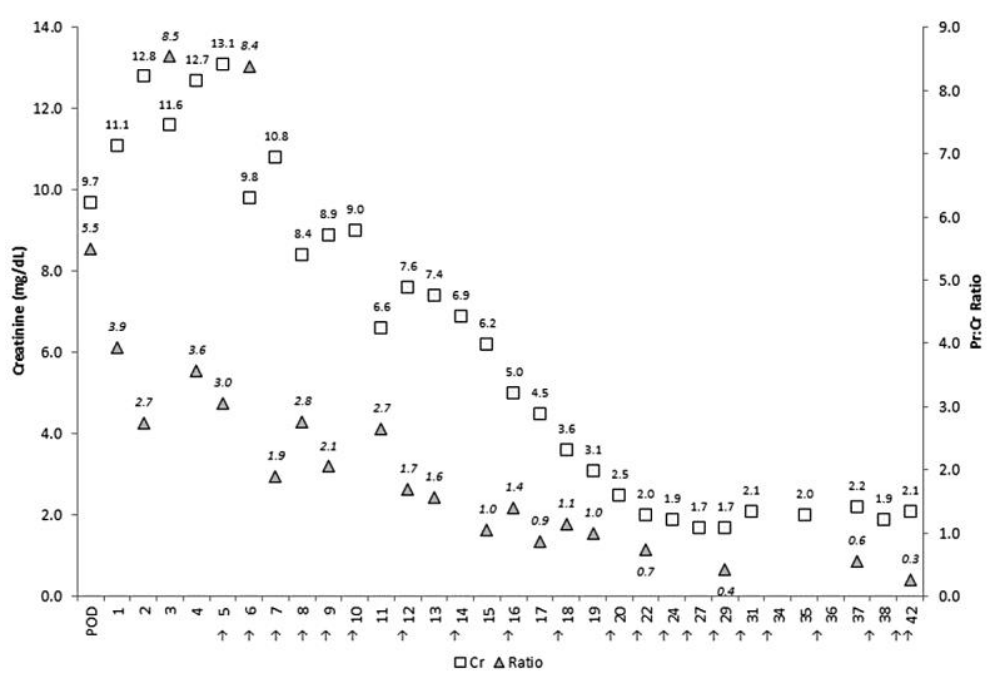

Fig. 1. Case 1, treatment course. Arrows depict therapeutic plasma exchange procedures.

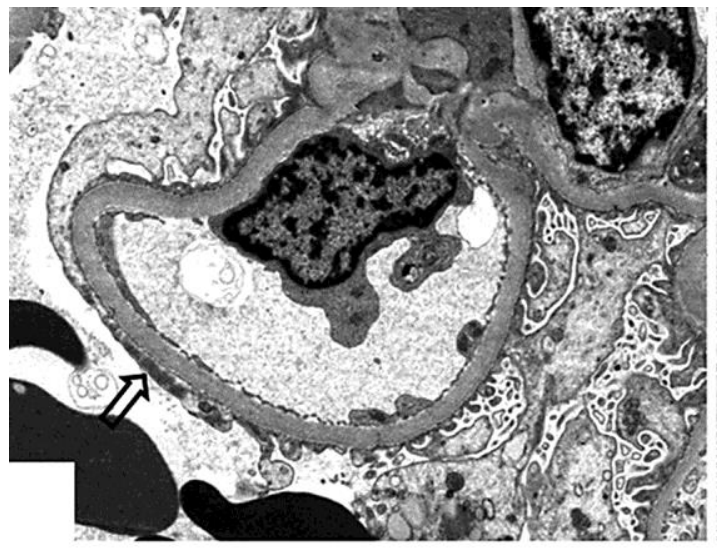

Pre-treatment

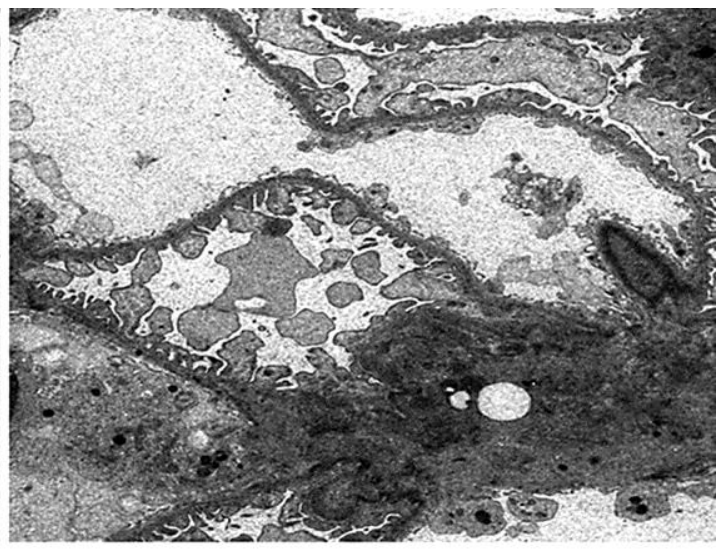

Post-treatment

Fig. 2. Histologic response. The pretreatment biopsy demonstrates moderate effacement (arrow) of the foot processes of the glomerular visceral epithelial cells and microvillous transformation changes, evidence of recurrent FSGS. There were patent capillary loops, normal endothelial fenestration, and no immune deposits. There was effacement of approximately half of the epithelial cell foot processes on electron microscopy. After improvement of $\mathrm{Pr}$ :Cr ratio from plasma exchange therapy, the posttreatment glomeruli show features of epithelial foot process recovery. There is markedly less effacement and minimal microvillous transformation changes. Electron microscopy shows less than one quarter of the foot processes effaced and the majority having a normal arrangement. 
Case Reports in

Nephrology

and Dialysis

\begin{tabular}{l|l}
\hline Case Rep Nephrol Dial 2016;6:53-60 \\
\hline DOI: 10.1159/000445428 & $\begin{array}{l}\text { @ 2016 The Author(s). Published by S. Karger AG, Basel } \\
\text { www.karger.com/cnd }\end{array}$ \\
\hline
\end{tabular}

Tran et al.: Treatment of Focal Segmental Glomerulosclerosis Recurrence in the Renal Allograft: A Report of Two Cases

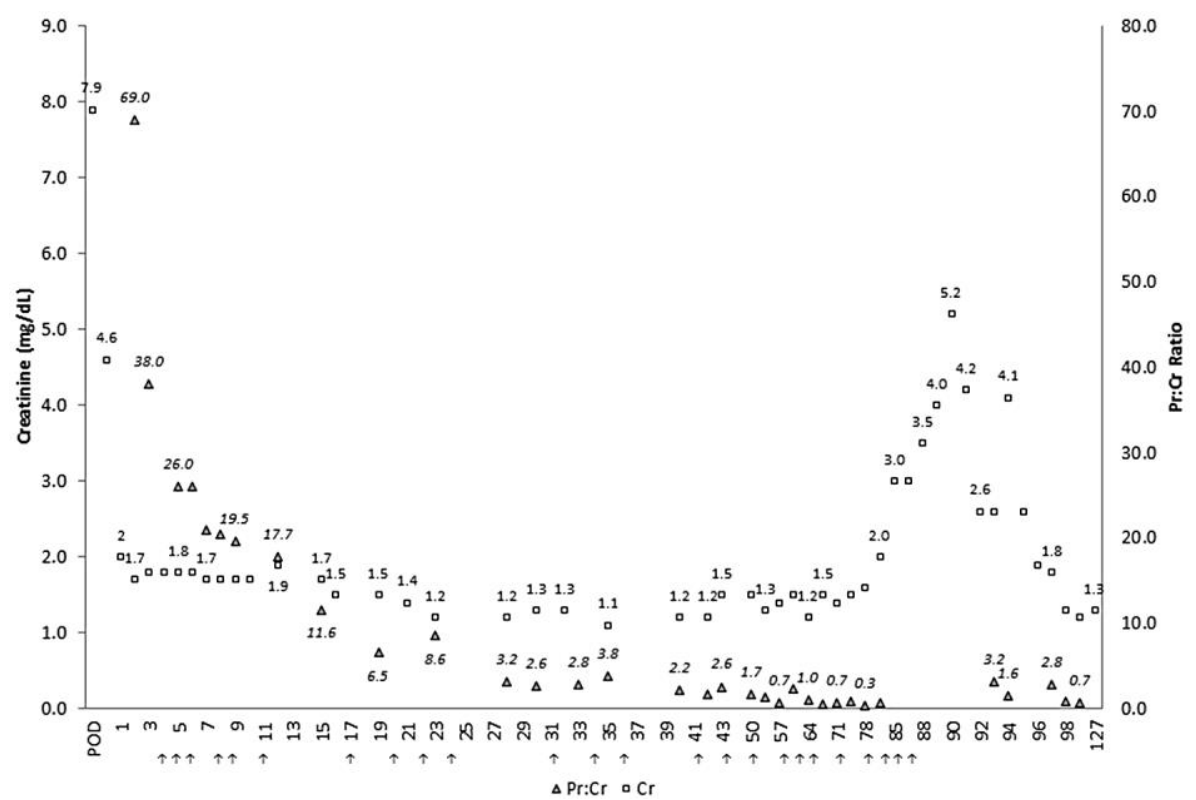

Fig. 3. Case 2, treatment course. Arrows depict therapeutic plasma exchange procedures. 